\title{
ASSESSORIA COMPUTACIONAL: desenvolvimento de newsbot para organizações financeiras
}

\author{
COMPUTATIONAL ASSISTANCE: newsbot development for financial organizations
}

ASESORÍA COMPUTACIONAL: desarrollo de newsbot para organizaciones financieras

\section{Alberto Marques \\ Professor doutor do Mestrado em Inovação em Comunicação e Economia Criativa da Universidade Católica de Brasília (UCB). É graduado em jornalismo. alberto.marques@gmail.com}

\section{0-0003-1861-2630}

\section{Suélem S. P. Barroso}

Mestre em Inovação em Comunicação e Economia Criativa (PPGCOM/UCB) e graduada em Comunicação Social - Jornalismo (UNIP). barroso.sue@gmail.com

0000-0002-7211-9313

Correspondência: Universidade Católica de Brasília, Departamento de Comunicação. Campus Taguatinga. QS 07 - Lote 01 - EPCT - Taguatinga, Brasília/DF - CEP: 71966-700.

Recebido em: 16.02.2021.

Aceito em: 16.04 .2021

Publicado em: 01.07.2021.

\section{RESUMO:}

Esta pesquisa objetiva desenvolver o Minimum Viable Product (MVP) de uma plataforma em nuvem que transforma dados estruturados em textos automatizados, para potencializar a produção de conteúdo nas Corretoras de Valores Mobiliários. Trata-se de Pesquisa Aplicada que combina diferentes técnicas para o desenvolvimento do MVP. Como percurso teórico para embasar o desenvolvimento do produto, perpassa a comunicação estratégica nas corporações, assim como a adoção de algoritmos e a automação de conteúdo na produção jornalística. Como alguns dos resultados alcançados, temos a lógica de infraestrutura macro do funcionamento do newsbot e os principais elementos para as inúmeras camadas de desenvolvimento de que uma aplicação dessa natureza necessita.

PALAVRAS-CHAVES: Comunicação estratégica; Estratégia organizacional; Conteúdo automatizado; Newsbot,

Algoritmos.

"Novas descobertas frequentemente aparecem quando se lê a situação de 'novos ângulos' e uma leitura mais ampla e variada pode criar uma gama também mais ampla e variada de possibilidades de ação". Gareth Morgan, 2011.

\section{Introdução}

As transformações socioculturais introduzidas pelas tecnologias de informação e comunicação são utilizadas como suporte para pensar estratégias interativas mediadas por computador nas organizações contemporâneas. Esse cenário envolve a utilização de novos ângulos de análise, com implicações de ordem teórica e metodológica para a comunicação organizacional (BARICHELLO, 2009).

A intensidade e a velocidade dos avanços já alcançados no campo da comunicação caracterizam de forma marcante a sociedade atual. Modificam-se, de um lado, veículos, processos, rotinas de trabalho e realidade do mercado relativa aos diversos meios de comunicação. Do outro, alteram-se necessidades de diálogo entre empresas, órgãos públicos, instituições, personalidades e seus diferentes públicos, 


\section{Cosycto
Oservotóno}

e-ISSN n ${ }^{\circ} 2447-4266$

Palmas, v. 7, n. 3, p. 1-29, jul.-set., 2021 http://dx.doi.org/10.20873/uft.2447-4266.2021v7n3a9pt

assim como demandas destes em relação àqueles. Para se manter como atividade útil e competente, é necessário acompanhar tais avanços, adaptando-se às novas demandas e necessidades de veículos e assessorados, que igualmente exigem dos assessores de comunicação crescentes e variadas habilidades (FERRARETTO, 2009).

Dessa forma, observa-se que algumas redações de jornais e agências de notícias pelo mundo estão utilizando, há um tempo, automação na produção textual e inteligência artificial para executar uma série de tarefas rotineiras (DANS, 2019).

Nos últimos 15 anos aproximadamente, os algoritmos ganharam espaço e se estabeleceram no trabalho científico social (BEER, 2016). Com a ajuda deles, diversas ações rotineiras como desburocratização de processos, elaboração de conhecimento ou produção de soluções para problemas reais passaram a ser "dataficadas" (transformadas em dados). O Big Data, assim como o desenvolvimento dos algoritmos, aumentou a capacidade de trabalhar com um grande volume de informação em velocidade e variedade consideráveis, aumentando, assim, a eficácia de ações preditivas e prescritivas sobre o comportamento social, econômico ou político de indivíduos conectados, a partir de sofisticados cruzamentos estatísticos (MAYERCHONBERGER; CUKIER, 2013).

Helbing et al. (2017) afirmam que os dados são considerados o petróleo do século 21 e que, em 2016, foram produzidos tantos dados quanto na história da humanidade até 2015. Compreender a interação entre coleta de dados em larga escala, análise algorítmica, práticas computacionais e produção de conhecimento público é um dos principais desafios metodológicos e filosóficos de nosso tempo (MANOVICH, 2011).

Adobe e Econsultancy (2019) explicam: empresas que tratam seus dados como um ativo competitivo fundamental e valioso, ao mesmo tempo respeitando a privacidade do cliente, podem usá-los para ajudar a impulsionar estratégias comerciais por meio de experiências do cliente aprimoradas, pois o consumidor está mais exigente e valoriza a sua autonomia.

Nesse contexto, as organizações têm necessidade de criar um design estratégico de mensagens cada vez mais alinhado aos diferentes tipos de audiência, e que, ao mesmo tempo, atenda aos objetivos de negócio comunicando essas mensagens com escala, precisão e velocidade, aumentando a personalização das comunicações. Isso significa comunicar não mais de forma massiva, mas de maneira personalizada. 


\section{Obsevisto}

e-ISSN no 2447-4266

Palmas, v. 7, n. 3, p. 1-29, jul.-set., 2021

http://dx.doi.org/10.20873/uft.2447-4266.2021v7n3a9pt

Considerando isso, a pergunta chave deste trabalho é: como uma organização financeira pode se valer do design estratégico de mensagens e da mediação algorítmica para gerir e utilizar os dados gerados, recebidos e armazenados, transformando-os em textos automatizados coerentes?

Para ajudar a respondê-la, o objetivo desta pesquisa é desenvolver um Minimum Viable Product (MVP) de uma plataforma web que transforma dados estruturados da Bolsa de Valores do Brasil em informes financeiros automatizados.

O processo de desenvolvimento do MVP sofreu diversas idas e vindas, porque é um sistema vivo em constante evolução. Neste trabalho, é possível encontrar a lógica de arquitetura de funcionamento macro do newsbot - criado do zero - assim como os principais elementos para as inúmeras camadas de desenvolvimento que uma aplicação dessa natureza necessita ter, o que vai muito além de um script feito em uma linguagem de programação como a Python.

\section{Lentes da comunicação estratégica}

Em um mundo cada vez mais complexo, as organizações disputam a atenção, admiração, afinidade, alinhamento e lealdade de todos os tipos de públicos, sejam eles clientes, funcionários, investidores e doadores, funcionários do governo, líderes de grupos de interesse especiais e o público em geral (HALLAHAN et al., 2007).

Hallahan et al. (2007) apresentam dois modelos de comunicação ${ }^{1}$. O primeiro é o chamado modelo de transmissão de comunicação, o qual conceitua a comunicação como a emissão unidirecional de informações. O modelo de Shannon e Weaver é um modelo de comunicação unidirecional amplamente citado, focado na transmissão de sinais através de um canal com uma capacidade de feedback limitada (SHANNON; WEAVER, 1949, apud HALLAHAN et al., 2007, p. 20). Essa abordagem é como uma mão de via única: apenas a organização fala o que deseja comunicar e o receptor, que é pouco ou nada ouvido, assume o papel de mero ouvinte, leitor, telespectador. Aqui a organização se comunica praticamente da mesma maneira sem levar em consideração os diferentes públicos e suas necessidades individuais.

O segundo é um modelo interativo que argumenta que a comunicação envolve a criação e a troca de significado entre as partes em uma atividade comunicacional (HALLAHAN et al., 2007). Neste modelo, podemos citar Wolton (2011), o qual afirma que comunicar é negociar e conviver. Não existe comunicação sem informação, e

1 Apesar de existirem outros modelos comunicacionais, citar e analisar todos eles estão além do escopo deste trabalho. 


\section{Obevisto}

e-ISSN no 2447-4266

Palmas, v. 7, n. 3, p. 1-29, jul.-set., 2021 http://dx.doi.org/10.20873/uft.2447-4266.2021v7n3a9pt

informar não é comunicar. A comunicação é sempre mais difícil por impor a questão da relação, ou seja, a questão do outro, e que não há informação sem um projeto de comunicação; nesse caso a informação é a mensagem, e a comunicação está conectada com a relação, a alteridade e o receptor (WOLTON, 2011).

O autor explica que a aceleração da produção e da transmissão de um número crescente de informações não é mais suficiente para criar um aumento de comunicação. Os receptores negociam, filtram, hierarquizam, recusam ou aceitam as incontáveis mensagens recebidas. O receptor está cada vez mais ativo para resistir ao fluxo de informações. Ontem, comunicar era transmitir, pois as relações humanas eram frequentemente hierárquicas. Hoje, é quase sempre negociar, pois os indivíduos e os grupos se acham cada vez mais em situação de igualdade (WOLTON, 2011).

Nesse sentido, as organizações se veem na necessidade de criar um design estratégico de mensagens cada vez mais alinhado aos diferentes tipos de audiência que elas possuem e que, ao mesmo tempo, atendam aos objetivos de negócio. $O$ newsbot apresentado nessa pesquisa tem como propósito auxiliar na produção estratégica dessas mensagens.

Por isso, as empresas precisam entender que mais pontos de contato e volume mais alto nas mensagens não se traduzem necessariamente em maior influência (KOTLER; KARTJAJAYA; SETIAWAN, 2017). É preciso destacar-se da multidão e conectar-se de forma significativa com os consumidores em apenas alguns poucos pontos de contato cruciais; na verdade, apenas um único momento de prazer inesperado com uma marca é o que basta para transformar um cliente em um fiel advogado (KOTLER; KARTJAJAYA; SETIAWAN, 2017).

Antes de entrarmos especificamente na produção de um design de mensagem estratégica, cabe frisar que tal mensagem está inserida em um contexto de uma estratégia institucional, em uma análise atenta da jornada do consumidor na qual se tem a atenção, interesse, desejo e ação mapeados a fim de alcançar os objetivos de negócio da organização. Uma mensagem avulsa e desprendida de qualquer estratégia produz pouco ou efeito nenhum em vários contextos e situações organizacionais.

Isso implica dizer que, se o MVP deste trabalho não estiver inserido dentro de uma estratégia institucional e de comunicação adequada, ele não será uma ferramenta eficaz para a organização, independentemente de sua natureza.

Desde o surgimento do International Journal of Strategic Communication (IJSC), em 2007, o termo "comunicação estratégica" tornou-se popular tanto na academia 


\section{Obevisto}

e-ISSN no 2447-4266

Palmas, v. 7, n. 3, p. 1-29, jul.-set., 2021 http://dx.doi.org/10.20873/uft.2447-4266.2021v7n3a9pt

quanto na prática como solução para muitos problemas pragmáticos. Os autores elencam quatro dimensões para comunicação estratégica (ZERFASS et al., 2018).

Primeiro, apresentam que o termo "comunicação estratégica" funciona como um substituto para "comunicação integrada", termo genérico para todos os tipos de comunicação orientada a objetivos, iniciada por organizações para abordar qualquer tipo de partes interessadas e audiências.

Segundo, há um crescente debate sobre o novo papel que a comunicação está assumindo nas empresas contemporâneas, grandes, privadas e de capital aberto que necessitam ser estratégicas e decisórias, em oposição a táticas e de apoio. A principal contribuição dessa visão é a noção de organização como ator corporativo, incorporado à sociedade e caracterizado por interesses, estruturas, processos, culturas e modos específicos de tomada de decisão interdependentes de outros níveis (macro e micro).

Terceiro, existe um interesse antigo, mas crescente, na comunicação no contexto do poder militar e nacional (GRAHAM, 2017; NOTHHAFT; SCHÖLZEL, 2015; PAUL, 2011, apud ZERFASS et al., 2018). Quarto, a "comunicação estratégica" é usada como uma terminologia alternativa para a disciplina estabelecida de relações públicas, sem alterar os objetos de pesquisa subjacentes ou as perspectivas desse campo (ZERFASS et al., 2018, p. 489).

A título de direcionarmos este estudo, seguiremos com a segunda abordagem de comunicação estratégica. Hallahan et al. (2007) expõem que a comunicação estratégica difere da comunicação integrada, porque seu foco é na forma como uma organização se comunica através dos esforços organizacionais. A ênfase está na aplicação da estratégia da comunicação e em como uma organização funciona como ator social para avançar em sua missão.

A capacidade de uma organização de se comunicar estrategicamente é constituída por uma infinidade de subprocessos que ocorrem entre colegas de trabalho, gerentes, diretoria, presidência e stakeholders externos diariamente. Portanto, é necessário considerar processos de interação não apenas como importantes em si mesmos, mas também como pertencentes da comunicação estratégica e do desempenho geral de uma organização (HEIDE et al., 2018).

É importante que a comunicação estratégica direcione a organização como um ator social que age para promover a si mesmo e aos seus produtos, suas causas e os movimentos sociais a que se associa por meio das ações intencionais dos seus líderes, colaboradores e profissionais de comunicação (RUÃO, 2016). 


\section{Obsevisto}

e-ISSN n² 2447-4266

Palmas, v. 7, n. 3, p. 1-29, jul.-set., 2021 http://dx.doi.org/10.20873/uft.2447-4266.2021v7n3a9pt

Nesse sentido, uma breve compreensão dos aspectos estratégicos pode, em alguma medida, trazer luz à discussão. Isso porque, no campo da comunicação, muitas vezes a estratégia tem aparecido como uma mola propulsora para aproximar as organizações cada vez mais de seus objetivos de negócio junto aos seus públicos.

Nessa perspectiva, a comunicação estratégica poderia ser mais bem aproveitada se estivesse presente em organizações que possuem uma estrutura como sistema vivo ou como de fluxo e transformação, pois organizações dessa natureza estão mais suscetíveis a inovação por desenvolverem a capacidade de transformar o ambiente de maneira mais rápida ou por terem maior flexibilidade para solucionar problemas de maneira pragmática.

Dito isso, a estratégia é entendida como uma prática social em que o ato de se fazer estratégia estaria orientado em responder onde, como e por quem esse trabalho é feito (SARAIVA et al. 2011). O "onde" responderia em que lugar está inserida no espaço e no tempo. Já o "como" focaria sobre o processo em que o pensamento se realiza, transformando-se em experiência. Por último, mas não menos importante, o "por quem" corresponderia aos atores sociais, atores esses que se sustentam em práticas para agir e cujas atividades são fundamentais para a sobrevivência da organização.

A comunicação é a "cola da organização", pois permite atingir a coordenação com um reduzido esforço e mínimo controle de custos (RUÃO, 2016).

Por esse ângulo, poderíamos dizer que, em linhas gerais, a comunicação estratégica é a confluência de práticas, e seria possível reunir alguns elementos vitais para seu desempenho, o que inclui a leitura de situações em que não existe um ponto de vista fixo e inabalável, assim como o estabelecimento da simbiose da estratégia institucional com a comunicação estratégica, as quais juntas ajudam a organização ou desenvolvimento de um determinado produto a se localizar no tempo e espaço para alcançar seus objetivos de negócios, seja do ponto de vista institucional ou comercial.

Dessa maneira, a comunicação estratégica poderia ser vista como um hub que conecta os objetivos de negócio da instituição com os ambientes interno e externo, considerando aspectos relevantes não-lineares da gestão da comunicação, como análise, planejamento, execução e avaliação.

Para a análise, poderiam ser incorporados: o benchmarking, com a finalidade de aprender e conhecer melhores práticas em outras empresas; o estudo de stakeholders, a fim de mapear e direcionar as atividades de comunicação e as técnicas de cenário 


\section{Obevisto}

e-ISSN no 2447-4266

Palmas, v. 7, n. 3, p. 1-29, jul.-set., 2021

http://dx.doi.org/10.20873/uft.2447-4266.2021v7n3a9pt

usadas para pensar em diferentes contextos em um esforço para preparar a empresa para o futuro (VOLK et al., 2017).

Já o planejamento contemplaria a missão e visão da estratégia corporativa; os scorecards de comunicação, usados para traduzir estratégias em ações; relatórios sobre os resultados, combinando os aspectos financeiros e indicadores não financeiros para mostrar como as comunicações geram valor; além do posicionamento da marca junto ao público de interesse.

Quanto à execução, a gestão de relacionamento com clientes, stakeholders, jornalistas e políticos é fundamental. Trata-se do gerenciamento da comunicação da mudança, que é uma abordagem estruturada para preparar e ajudar os membros da organização a se adaptarem com sucesso à mudança organizacional (VOLK et al., 2017).

O quarto elemento, o qual corresponde à avaliação, foca nos relatórios integrados que explicam como uma organização cria valor sob seis aspectos diferentes: financeira, comercial, manufatura, intelectual, humano, social/relacionamento e capital natural; engloba também um dashboard no qual são apresentadas as informações essenciais, assim como a avaliação do processo que se concentra no desenvolvimento, progresso e busca constante de melhorias do projeto.

Os quatro macroelementos citados compreendem algumas atividades executadas por membros de uma organização das áreas de negócios, operações, comunicação e marketing. Isso indica que a comunicação estratégica é transversal ao transitar por diferentes setores da organização. $O$ ato de se fazer estratégia não é um manual ou algo rígido.

\section{Produção de conteúdo automatizado e o jornalismo}

Na comunicação, o jornalismo é uma das áreas que mais desenvolveu a escrita mediada por algoritmos. O jornalismo computacional é uma confluência de práticas jornalísticas e conhecimentos tradicionalmente associados às Ciências da Computação, a fim de desenvolver matérias e notícias fundamentadas nos objetivos sociais e nos valores do jornalismo em um ambiente de convergência tecnológica (AZZELLINI; PESCHANSKI, 2018). Diakopoulos (2011) afirma que o jornalismo computacional é a aplicação de computação e do pensamento computacional às atividades do jornalismo, incluindo coleta de informações, organização e produção de sentido, além da difusão e resposta pública às informações das notícias; tudo isso mantendo os valores centrais do jornalismo, como a precisão e a verificabilidade. 


\section{Obsevisto}

e-ISSN no 2447-4266

Palmas, v. 7, n. 3, p. 1-29, jul.-set., 2021 http://dx.doi.org/10.20873/uft.2447-4266.2021v7n3a9pt

Cabe dizer que o pensamento computacional é entendido como a capacidade de navegar por diferentes níveis de abstração (AZZELLINI; PESCHANSKI, 2018). No jornalismo, por exemplo, a forma de pensar computacionalmente auxilia no entendimento de como funciona uma determinada tecnologia e quais as possíveis apropriações profissionais podem-se fazer a partir dela.

Além disso, ajuda na compreensão dos processos de inovação disparados a partir da sua estrutura. Pode ser justamente pela aquisição do novo conhecimento que se estabelece a ponte entre as funções do jornalismo, na atual sociedade, e a capacidade de obter informações de relevância social por intermédio de sistemas computacionais (LIMA JÚNIOR, 2012 apud AZZELLINI; PESCHANSKI, 2018).

Uma das especificidades que caracterizam o jornalismo computacional é que ele tem como base narrativas estruturadas, ou seja, narrativas desenvolvidas a partir de dados estruturados com graus de organização, sistematizados e arranjados por padrões de valores. É nesse horizonte que surge o jornalismo automatizado, um fenômeno relativamente novo na área do jornalismo computacional. Termos como jornalismo robótico, jornalismo automatizado, jornalismo algorítmico ou jornalismo escrito à máquina dominam a mídia e o discurso científico (DÖRR, 2016).

O jornalismo automatizado, termo que será empregado neste trabalho, utiliza a geração de linguagem natural (em inglês Natural Language Generation - NLG), tecnologia definida como software e sistemas de computador que produzem automaticamente a representação da linguagem humana (natural) a partir de uma representação computacional de informação (REITER; DALE, 2000).

O jornalismo automatizado se refere ao processo de usar software ou algoritmos para gerar automaticamente novas histórias sem intervenção humana, depois de uma programação inicial de algoritmos, é claro (GRAEFE, 2016, p. 14, tradução nossa). Portanto, uma vez que um algoritmo é desenvolvido, ele permite automatizar cada passo no processo da produção de uma notícia, da coleta e análise de dados, para sua criação e publicação. Esse método funciona com histórias baseadas em fatos quando os dados limpos, estruturados e confiáveis estão disponíveis. Em cada situação, algoritmos podem criar conteúdos em larga escala, personalizando-os para as necessidades individuais de cada leitor, mais rápido, com um custo mais baixo e potencialmente com menos erros que qualquer jornalista humano (GRAEFE, 2016, p. 14 , tradução nossa).

A automação pode ser vista como parte de uma transformação epistemológica maior e mais longa no jornalismo, conhecida como a "virada quantitativa" 


\section{Obsevisto}

(CODDINGTON, 2015), rearticulando valores e práticas de apreensão e representação da realidade social e tornando as racionalidades do jornalismo cada vez mais dependentes de quantificação e computação (MILOSAVLJEVIĆ; VOBIČ, 2019). Vale sempre lembrar que, apesar de estarmos falando de jornalismo, teoricamente seria possível empregar as ideias discutidas até aqui em diversos segmentos da vida social moderna.

O jornalismo automatizado é definido como uma produção autônoma de conteúdo por meio de algoritmos de computador (WÖLKER; POWELL, 2018). O conceito pode ser entendido também por um conjunto de habilidades computacionais necessárias para coletar, processar, combinar e visualizar dados a fim de produzir notícias. Por fim, complementando tudo o que foi dito até aqui, Strauss (2018) afirma que o jornalismo automatizado utiliza um conjunto preciso de dados para dar sentido à informação (TABARY; PROVOST; TROTTIER, 2015).

Sobre a automação, é relevante complementar que existem diferentes níveis de automação, e compreender esses graus é uma questão fundamental. Diakopoulos (2019) explica que a automação, por sua vez, foi definida como "um dispositivo ou sistema que realiza (parcial ou totalmente) uma função que era anteriormente, ou concebivelmente, realizada (parcial ou totalmente) por um operador humano".

Já o termo Inteligência Artificial pode ser compreendido como um sistema de computador "capaz de realizar tarefas que normalmente requerem inteligência humana". O termo "tecnologia autônoma" implica uma versão de automação completa em que um sistema opera sem intervenção humana; não obstante o design, o trabalho de manutenção é feito por humanos, o que todos os sistemas projetados necessitam. A autonomia completa é um extremo em um espectro de opções que combinam humanos e computadores (DIAKOPOULOS, 2019, p. 16, tradução nossa). 
Figura 1. Níveis de automação que combinam mais ou menos com o esforço humano e automação.

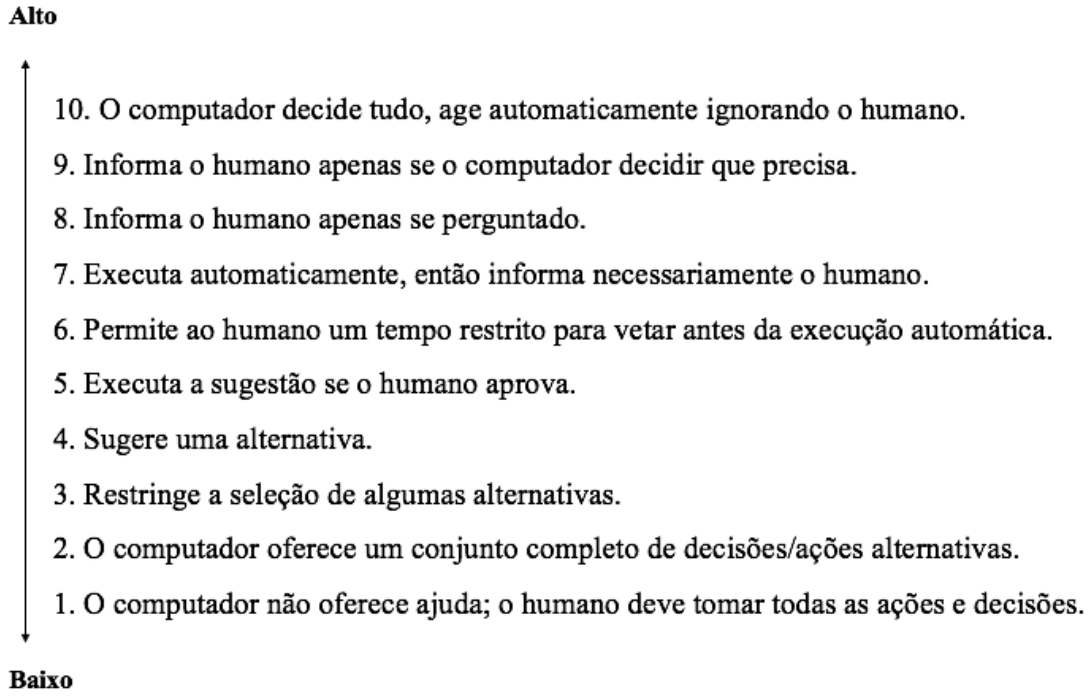

Fonte: Diakopulos (2019, p. 17), figura traduzida pelos autores (tradução livre).

Ao observar a figura acima, é possível identificar que, em todos os aspectos, o humano é peça fundamental, seja para o design, tomada de decisões completas ou parciais, além da manutenção da aplicação. Após uma breve análise, poderíamos dizer que o jornalismo automatizado perpassa os pontos sete e oito, e que essa relação híbrida humano-máquina não anula o ser humano; pelo contrário, pode potencializar sua capacidade criativa e crítica, proporcionando, então, análises mais profundas, entrevistas mais rebuscadas, percepções da pauta mais afinadas e estratégias mais assertivas.

As soluções atuais variam de um código simples que extrai números de uma base dados, como os que são usados para preencher os espaços em branco em modelos de histórias pré-escritas, para abordagens mais sofisticadas que analisam dados a fim de obter informações adicionais e criar narrativas mais atraentes (GRAEFE, 2016).

Figura 2. Como algoritmos geram notícias. 

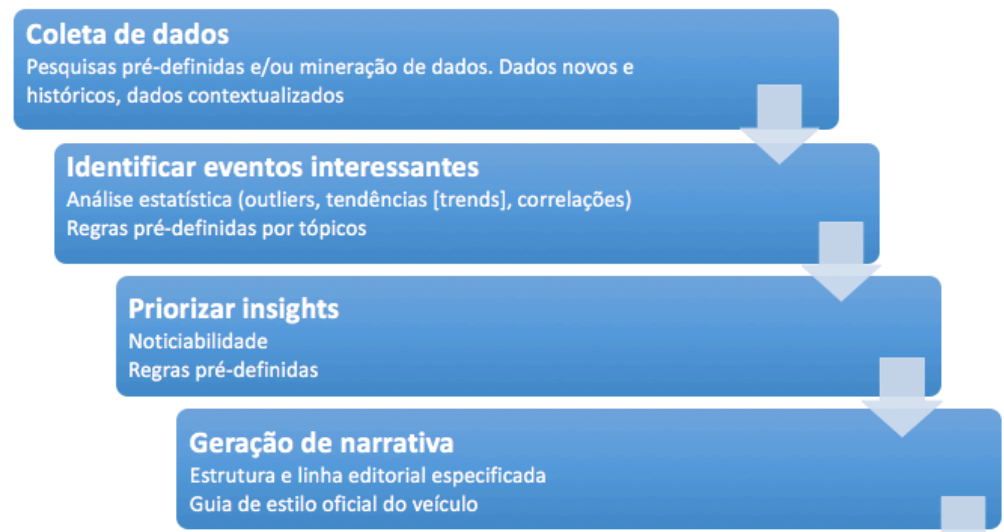

Publicar história

Fonte: Graefe (2016).

Algoritmos de machine learning tomam decisões baseados em dados e existe pelo menos quatro tomadas de decisões que algoritmos fazem: priorização, classificação, associação e filtro, as quais podem ser compostas ainda por várias outras subdecisões (DIAKOPOULOS, 2019). Por exemplo, para obter um resumo de notícias, cada algoritmo deve primeiro filtrar ou selecionar um subconjunto de sentenças representativas da notícia e, em seguida, priorizá-las em termos de importância para o usuário, antes de apresentá-la no resumo. Outras composições de decisões também são possíveis. 
Figura 3. Diagrama das quatro decisões algorítmicas fundamentais.
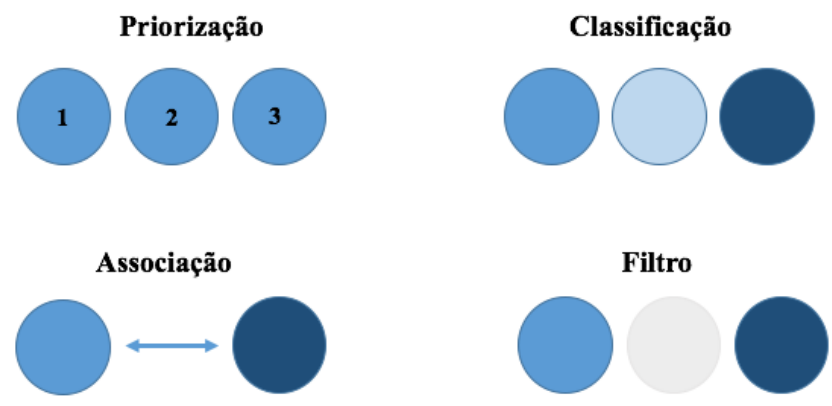

Fonte: Diakopulos (2019, p. 21).

Em resumo, algoritmos podem fazer tarefas cognitivas realizando cálculos baseados em equações ou transformando bits digitais em palavras e símbolos com enorme rapidez, assim como realizar tomada de decisões relacionadas a priorização, classificação, associação, filtro e composições a partir das decisões basilares (DIAKOPOULOS, 2019).

Ao compreender essa lógica em que a notícia é gerada automaticamente e decisões básicas são tomadas de maneira praticamente autônoma, as possibilidades se mostram abundantes.

\section{Método e técnicas de pesquisa}

O método científico dessa pesquisa é o hipotético-dedutivo. $E$, se o método é o caminho (LAKATOS, 2010), poderíamos então dizer que as técnicas de pesquisa seriam o modo de caminhar. Nesse sentido, Lakatos (2010) explica que as técnicas de pesquisa se dividem em duas esferas: documentação indireta, abrangendo a pesquisa documental e a bibliográfica; e a documentação direta, a qual se subdivide em observação direta intensiva (observação, entrevista) e observação direta extensiva (questionário, formulário, medidas de opinião e de atitudes, testes, sociometria, análise de conteúdo, história de vida, pesquisa de mercado).

Utilizamos como técnica de pesquisa a documentação indireta para a dimensão bibliográfica e a documentação direta, no aspecto da observação direta extensiva, com a aplicação de um questionário online (respondido por escrito e sem a presença do pesquisador (LAKATOS, 2010); com as Corretoras de Valores Mobiliários (CVMs) XP Investimentos, Guide Investimentos e Terra Investimentos para mapear aspectos que poderiam nortear o desenho do MVP.

Os aspectos metodológicos desta pesquisa podem ser assim vistos: 
Figura 4. Esquema da metodologia de pesquisa.

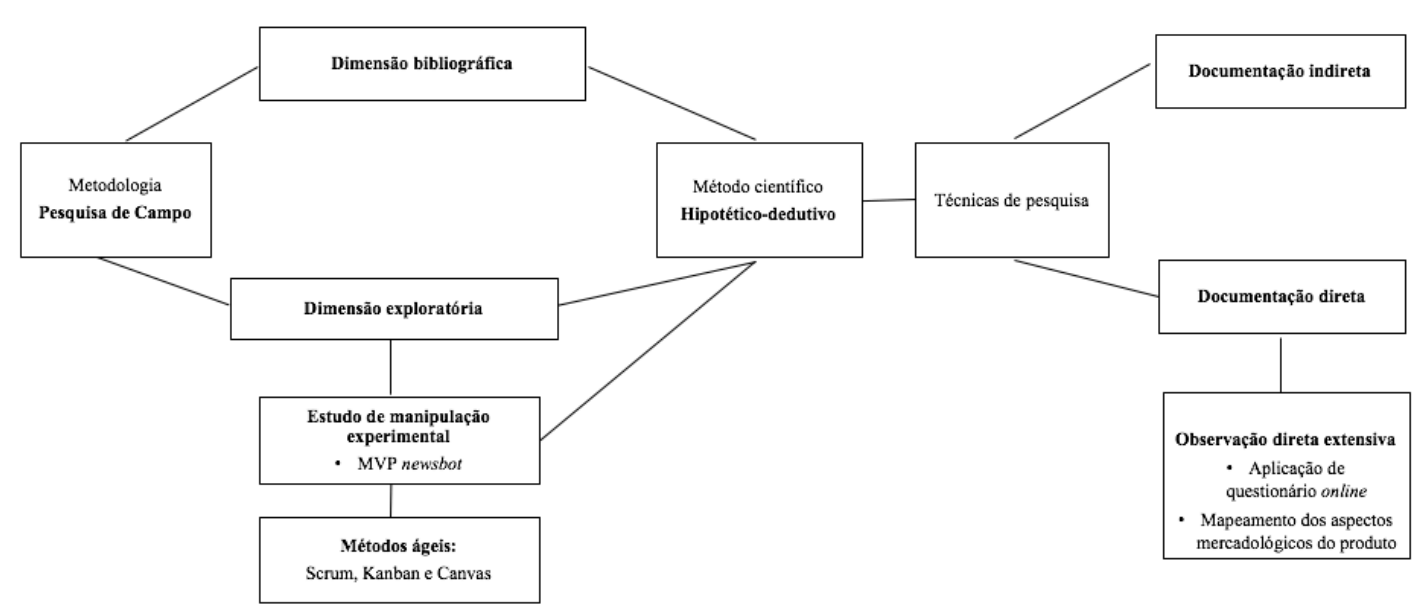

Fonte: Os autores.

\section{Processos de desenvolvimento do MVP}

Sommerville (2007) explica que um novo software deve ser desenvolvido rapidamente para aproveitar as novas oportunidades e responder às pressões competitivas do mercado e que, muitas vezes, não estão voltados para a rapidez em seu desenvolvimento. Geralmente os processos de desenvolvimento rápido de software são projetados para criar uma aplicação útil rapidamente, sendo disponibilizado em uma série de incrementos, e cada um deles inclui uma nova funcionalidade do sistema. Por isso, o MVP apresentará os incrementos de necessidade primária do projeto: escrever um texto automatizado a partir de dados estruturados.

Nas décadas de 1980/1990, entendia-se que a melhor maneira de obter o melhor software era por meio de cuidadoso planejamento de projeto. A insatisfação com esse tipo de abordagem possibilitou o surgimento dos métodos ágeis para entregar um software de trabalho rapidamente aos clientes, com alterações para interações posteriores do sistema (SOMMERVILLE, 2007).

Extreme Programming, Scrum, Crystal e Kanban são alguns tipos de métodos ágeis aplicáveis ao desenvolvimento de software. Embora todos esses sejam baseados na noção de desenvolvimento e entrega incrementais, cada um deles propõem processos diferentes para conseguir isso (SOMMERVILLE, 2007). Em relação aos métodos ágeis de trabalho, conciliamos Scrum e Kanban para desenvolver o protótipo 
e Canvas para mapear os aspectos mercadológicos em que a aplicação pode vir a ser inserida.

O Scrum é um método ágil, pois segue os princípios do Manifesto Ágil ${ }^{2}$ (SOMMERVILLE, 2018). Considerado também um framework (CRUZ, 2018), é usado no gerenciamento rápido de projetos para a criação e desenvolvimento de qualquer produto complexo, principalmente por ser interativo e incremental, o que otimiza a previsibilidade e o controle de riscos. A ideia principal do Scrum é permitir que um pequeno time de pessoas trate e resolva problemas complexos e adaptativos enquanto entrega produtos de forma criativa (CRUZ, 2018). Neste trabalho, tomamos o Scrum como um framework.

Para a implementação de qualquer controle de processos empíricos no Scrum, são necessários três pilares: transparência, inspeção e adaptação (CRUZ, 2018). Ao visualizar esses três pilares, iniciam-se as sprints, momento no qual de fato o jogo acontece. Cruz (2018) apresenta quatro eventos formais que compõem a sprint. planejamento, reunião, revisão e retrospectiva. Dentro do Scrum há também divisão de papéis e responsabilidades. Os times são pequenos e realizam eventos com uma duração fixa. Basicamente, o time Scrum é composto por três papeis: Scrum Master (SM), Product Owner (PO) e o Time de Desenvolvimento (TD) (CRUZ, 2018).

O SM é o responsável por garantir que o Scrum seja entendido e aplicado; ele faz o papel do técnico do time. O PO, principal gerenciador do backlog do produto, garante o valor do trabalho realizado pelo time e, além de manter o backlog do produto, torna-o visível a todos. Já o TD executa o desenvolvimento e transforma o backlog do produto em incrementos de funcionalidades, criando um sistema pronto que possa ser entregue ao cliente.

O projeto de desenvolvimento do MVP desta pesquisa adota inicialmente alguns elementos do Scrum para que, quando a aplicação estiver disponível para o público empresarial, o framework possa ser aplicado em sua totalidade. Em relação aos papéis e responsabilidade do Scrum dentro do projeto, temos as posições de SM e PO ocupadas pelos autores da pesquisa e duas programadoras como TDs.

Outra abordagem utilizada no desenvolvimento do protótipo, o Kanban, é um método de fabricação orientado para a produção em série, sendo seu desenvolvimento creditado à Toyota Motor Company. É aplicável apenas em sistemas de produção 


\section{Observisotório}

e-ISSN n² 2447-4266

Palmas, v. 7, n. 3, p. 1-29, jul.-set., 2021 http://dx.doi.org/10.20873/uft.2447-4266.2021v7n3a9pt

discreta e repetitiva (LOBO, 2010). Aplicamo-lo na ferramenta online Trello para ter, de maneira organizada, o fluxo de trabalho do SM/PO com o TD em relação às sprints.

Em relação ao MVP, o projeto assume o modelo evolucionário como ciclo de vida do software ou processo de software. O ciclo de vida, termo utilizado neste trabalho, é um conjunto de atividades que leva à produção de um produto de software (SOMMERVILLE, 2007).

A abordagem de desenvolvimento evolucionário se baseia na ideia de desenvolvimento de uma implementação inicial, expondo o resultado aos comentários do usuário e refinando esse resultado por meio de várias versões, até que seja desenvolvido um sistema adequado (SOMMERVILLE, 2007).

Assim, a vantagem de um processo de software baseado na abordagem evolucionária é que a especificação pode ser desenvolvida de forma incremental, em que esse é o melhor método de desenvolvimento para sistemas de pequeno e médio porte (até 500 mil linhas de código, caso do MVP deste trabalho). À medida que o projeto do newsbot avançar e alcançar a dimensão de grande porte, futuramente pode-se incorporar um processo misto, absorvendo características de outros modelos.

Neste trabalho, usamos o tipo de prototipação throwaway para resolver as incertezas na especificação da aplicação, conforme figura abaixo, cujo objetivo é compreender os requisitos do cliente e, a partir disso, desenvolver melhor a definição de requisitos para o sistema (SOMMERVILLE, 2007).

Figura 5. Modelo de desenvolvimento evolucionário.

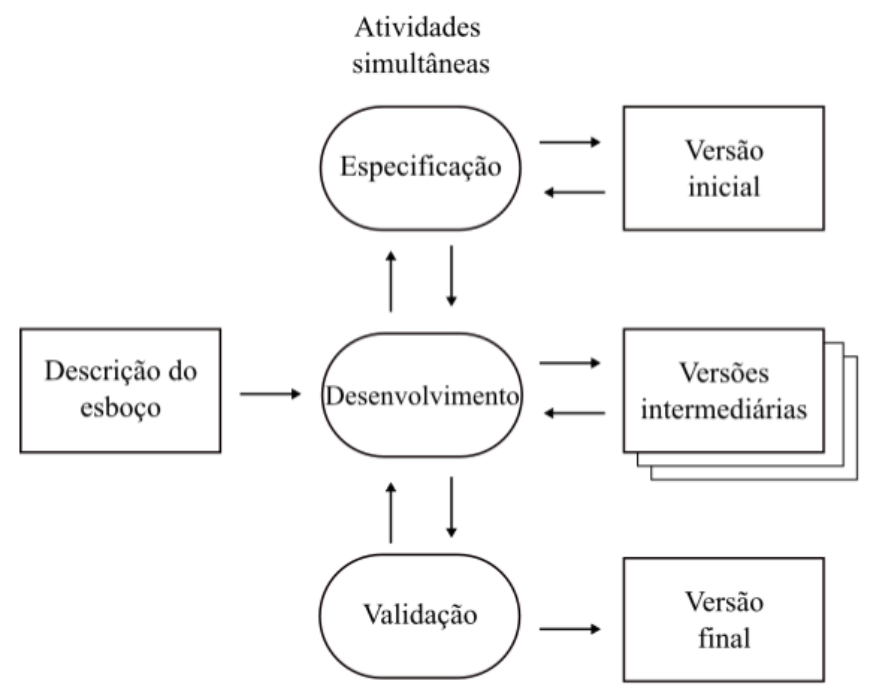

Fonte: Sommerville (2007). 


\section{Obevisto}

e-ISSN n ${ }^{\circ} 2447-4266$

Palmas, v. 7, n. 3, p. 1-29, jul.-set., 2021 http://dx.doi.org/10.20873/uft.2447-4266.2021v7n3a9pt

O desenvolvimento do MVP está dividido em três etapas: (i) especificação e projeto; (ii) desenvolvimento; e (iii) teste (SOMMERVILLE, 2007). Na primeira, não há especificação detalhada de sistema, e a documentação de projeto é minimizada ou gerada automaticamente, contemplando: planejamento estratégico global do projeto, desenho inicial do funcionamento macro do software, cronograma, definição de servidores, contratação de equipe e mapeamento de futuros desafios da aplicação.

A segunda é o sistema desenvolvido em uma série de incrementos, focando no desenvolvimento propriamente dito, no qual cada incremento é conduzido por uma sprint de no máximo duas semanas, elemento do framework Scrum, em conjunto com o Kanban.

A terceira etapa está relacionada às interfaces e ao usuário do sistema, que gera uma interface baseada na web para um navegador. Para isso, considera os ciclos de testes, validações, implementação de melhorias e métricas. Cada incremento é desenhado, desenvolvido e testado antes da próxima especificação de aperfeiçoamento ou novo incremento.

Para mapearmos os aspectos mercadológicos do MVP, utilizamos o Business Model Generation, o Canvas de Modelo de Negócios, um esquema para descrever, visualizar, avaliar e alterar modelos de negócios (OSTERWALDER; PIGNEUR, 2011).

\section{Estudo de manipulação experimental: o MVP}

O produto desenvolvido por esta pesquisa é um MVP de uma plataforma web que transforma dados estruturados da Bolsa de Valores do Brasil em informes financeiros automatizados, a partir de templates dinâmicos, combinando as inteligências humana e artificial ${ }^{3}$ para potencializar a produção de conteúdo nas CVMs que necessitam escrever aos diferentes tipos de investidores com escala, precisão e velocidade, a fim de dar vazão ao volume crescente das informações do mercado financeiro.

No primeiro momento, o newsbot começará a aprender e escrever sobre o mercado financeiro brasileiro e, posteriormente, outros segmentos serão incorporados ao aprendizado. Os textos automatizados são produzidos em português; outros idiomas como inglês e espanhol estão previstos para o estágio mais avançado da aplicação.

3 A inteligência artificial será incorporada ao MVP em estágio mais avançado da aplicação. 


\section{Obevisto}

e-ISSN n ${ }^{\circ} 2447-4266$

Palmas, v. 7, n. 3, p. 1-29, jul.-set., 2021

http://dx.doi.org/10.20873/uft.2447-4266.2021v7n3a9pt

O desenvolvimento do protótipo da plataforma segue as boas práticas de requisitos não funcionais da ISO/IEC 25010:2011, a qual determina quais características de qualidade considerar ao avaliar as propriedades de um produto de software.

Com relação ao modelo de qualidade de um sistema, a princípio, o MVP engloba adequação funcional, eficiência de desempenho, segurança e manutenção. As demais características (compatibilidade, usabilidade, confiabilidade e portabilidade) serão incorporadas em estágio posterior (ISO/IEC, 2011).

Figura 6. Características e subcaracterísticas do modelo de qualidade do produto definido na

ISO/IEC 25010:2011.

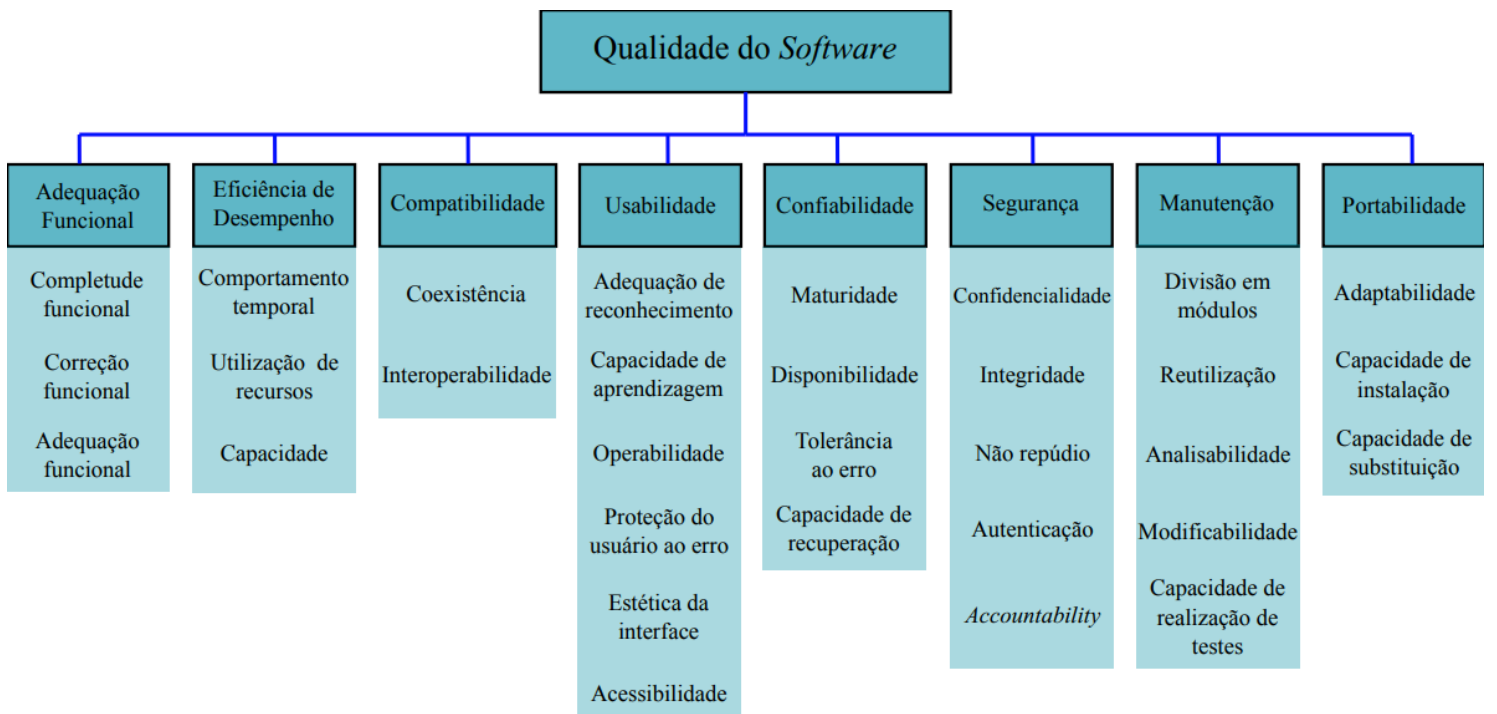

Fonte: ISO/IEC 25010:2011, tradução livre dos autores.

A linguagem de programação utilizada para o desenvolvimento do MVP é a Python que, linguagem orientada a objetos, permite que dados e métodos sejam encapsulados e reutilizados facilmente. Como linguagem dinâmica, possibilita que atributos sejam adicionados aos objetos em tempo real e que variáveis sejam digitadas 


\section{Obsevisto}

e-ISSN n² 2447-4266

Palmas, v. 7, n. 3, p. 1-29, jul.-set., 2021 http://dx.doi.org/10.20873/uft.2447-4266.2021v7n3a9pt

dinamicamente, facilitando o desenvolvimento rápido. Possui uma extensa biblioteca, incluindo componentes para programação gráfica, processamento numérico e conectividade da web (BIRD; KLEIN; LOPER, 2009).

Bibliotecas de código-aberto de inteligência artificial e aprendizado de máquina (Keras, TensorFlow e Scikit-learn), de análise e processamento de dados científicos (NumPy e SciPy), de análise de dados genéricos (Pandas); de visualização de dados (Seaborn) e de processamento de linguagem natural (Natural Language Toolkit (NLTK)) aceleram o processo de desenvolvimento de soluções, pois oferecem um conjunto de ferramentas e implementações prontas, testadas e mantidas pela comunidade, eliminando a necessidade de reconstruir um novo arcabouço computacional, o que permite focar em novas aplicações. As bibliotecas em uso inicialmente no desenvolvimento do newsbot são TensorFlow, Pandas e NLTK.

O Integrated Development Environment (IDE) no qual o software é desenvolvido é o PyCharm. Nele, é possível escrever e editar o código-fonte, depurar e efetuar testes. Para transformar o código-fonte em bytecode, é utilizado o processo de interpretação de código - uma vez que o Python é uma linguagem interpretada garantindo a flexibilidade de manutenção do software em produção e eliminando a necessidade de recompilação do código para funcionar em diferentes ambientes. $O$ gerador de bytecode utilizado para permitir que o software seja executado é o interpretador do Python (uma máquina virtual que converte código-fonte em bytecode).

O código-fonte do newsbot está distribuído em duas frentes que nomeamos hard code (código-fonte do funcionamento do software, em Python) e web interface code (código destinado para a interface web, em Django - framework gratuito e de código aberto da Python Web, que incentiva o desenvolvimento rápido, e um design limpo e pragmático da interface) (DJANGO, 2005).

Os códigos-fonte hard code e web interface code são desenvolvidos em ambiente local (PyCharm). A partir daí, faz-se o upload deles para a pasta do projeto no GitHub, que conecta automaticamente, depois de configurados, com o Heroku, servidor cloud para desenvolvimento e testes iniciais da aplicação e banco de dados. Esse ambiente serve para que o time de desenvolvedores possa desenvolver, aperfeiçoar e testar o código. Os servidores do ambiente de homologação e produção na nuvem, tanto para a aplicação quanto para o banco de dados, serão os do Heroku e Google Cloud Platform, respectivamente. 
Para guiar o desenvolvimento do front-end, criamos o layout das principais telas da interface web do protótipo da aplicação: tela login/senha, tela dashboard e tela geração do texto automatizado.

Figura 7. Tela ilustrativa de login e senha da aplicação.

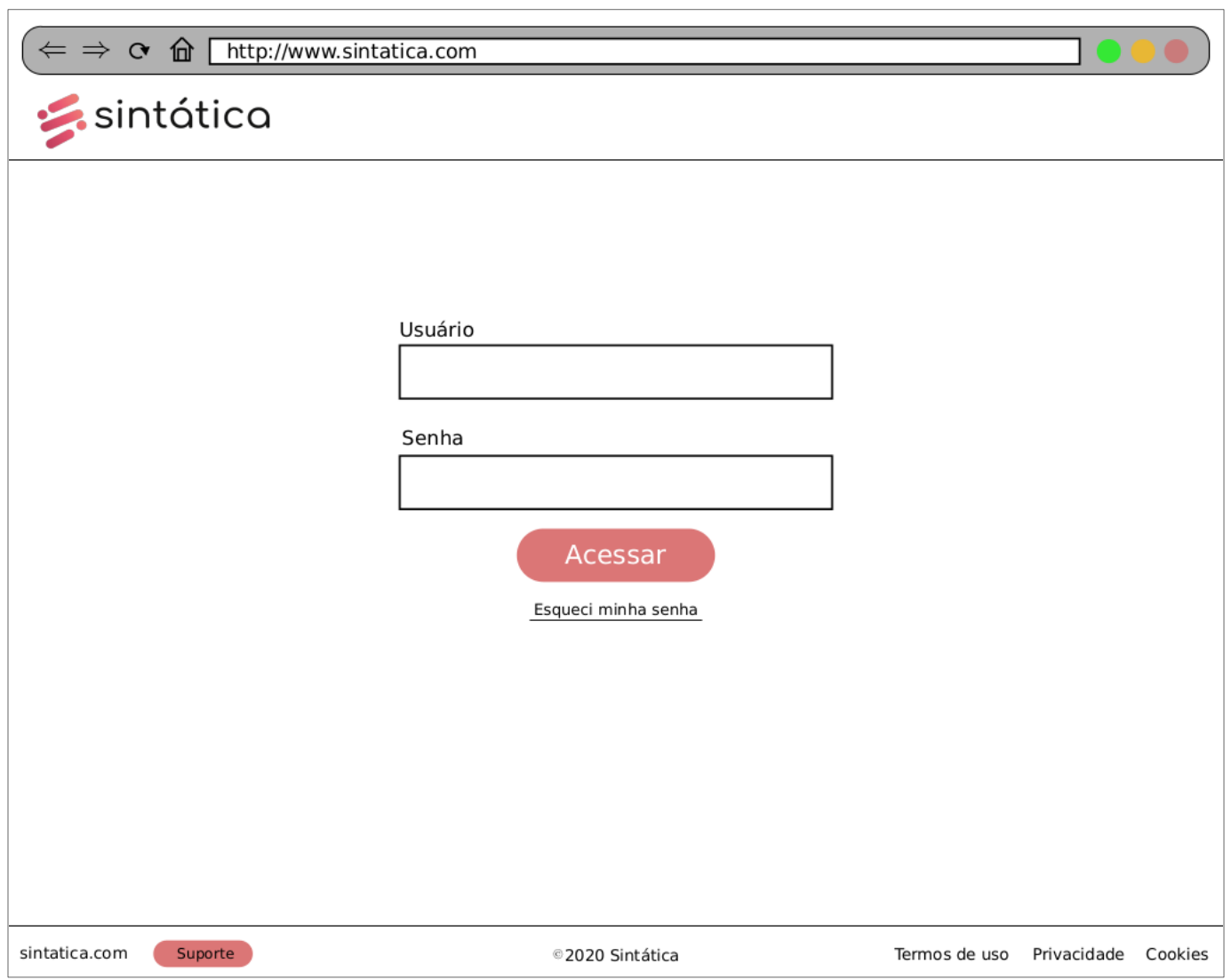

Fonte: Os autores.

A segunda tela principal é a do dashboard, na qual o usuário poderá ver as atividades realizadas por quem e quando, projetos criados, integrações com outros sistemas e aplicações, métricas relacionadas aos projetos criados, acesso para os membros de uma determinada equipe, configurações gerais da plataforma, ferramenta de busca, tracking das telas acessadas, acesso às preferências do usuário, suporte, criação de um novo projeto e download do conteúdo já criado.

A princípio, os recursos oferecidos pela tela do dashboard para o MVP estão focados na aba Overview (Figura 8) e no botão Novo projeto (Figura 8), que conduz o usuário para a tela de geração de texto automatizado. Isso porque todos os esforços neste trabalho estão direcionados para o desenvolvimento e aperfeiçoamento do hard code e das integrações necessárias entre os códigos-fonte. 
Figura 8. Tela ilustrativa do dashboard da aplicação.

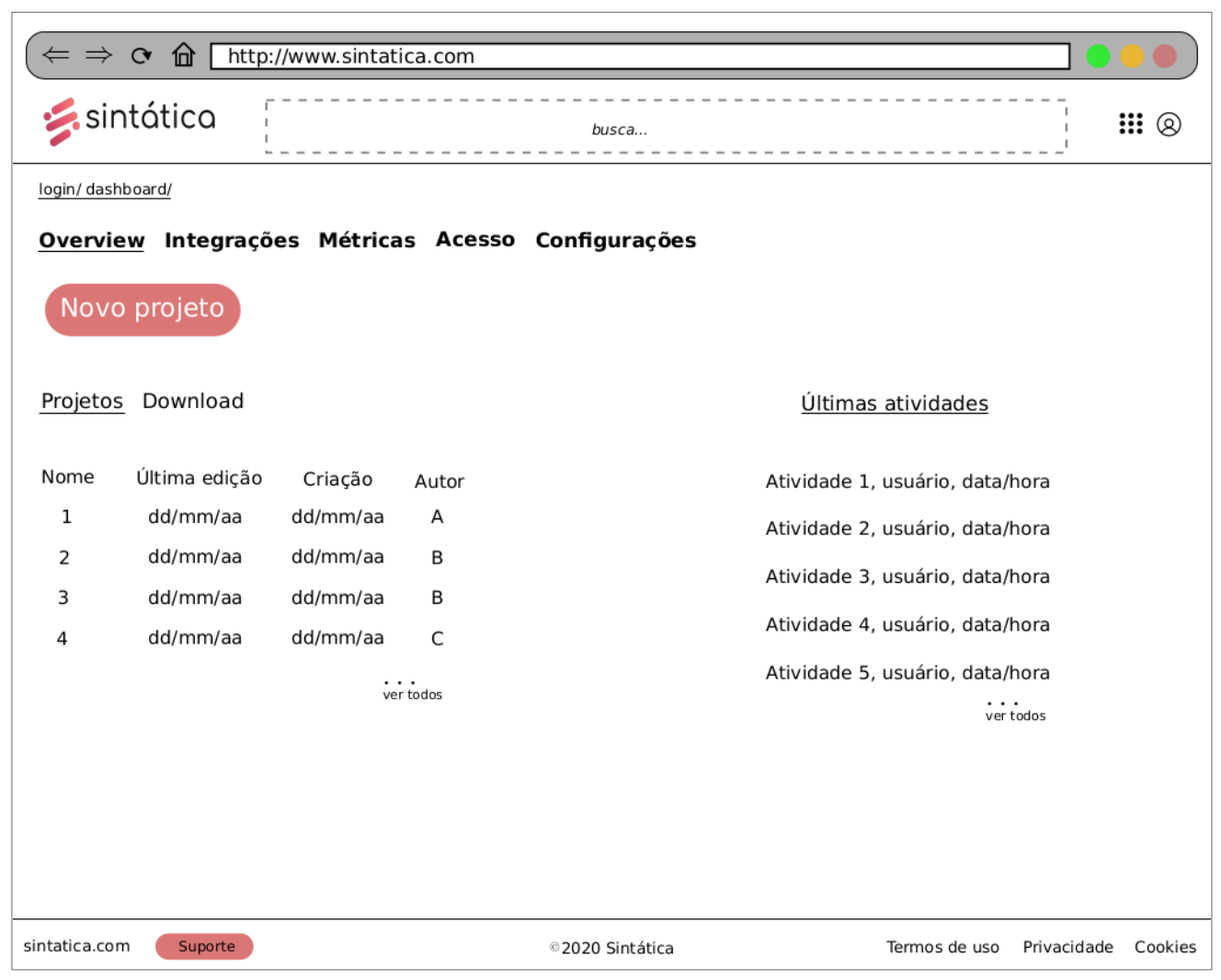

Fonte: Os autores.

A tela de geração do texto automatizado é onde o usuário pode selecionar os filtros de Área (finanças), Tema (setor e subsetor da Bolsa de Valores), Formato (informe), Audiência (investidor pessoa física; investidor corporativo) e Data (calendário) para então gerar o texto automatizado, que aparecerá no box ao lado direito da tela. As funcionalidades para inserir mais dados, adicionar sinônimos, revisar gramaticalmente texto e de download serão incrementos adicionados futuramente. $\mathrm{O}$ único disponível para a versão alpha do MVP será Reescreva. 
Figura 9. Tela ilustrativa geração de texto da aplicação.

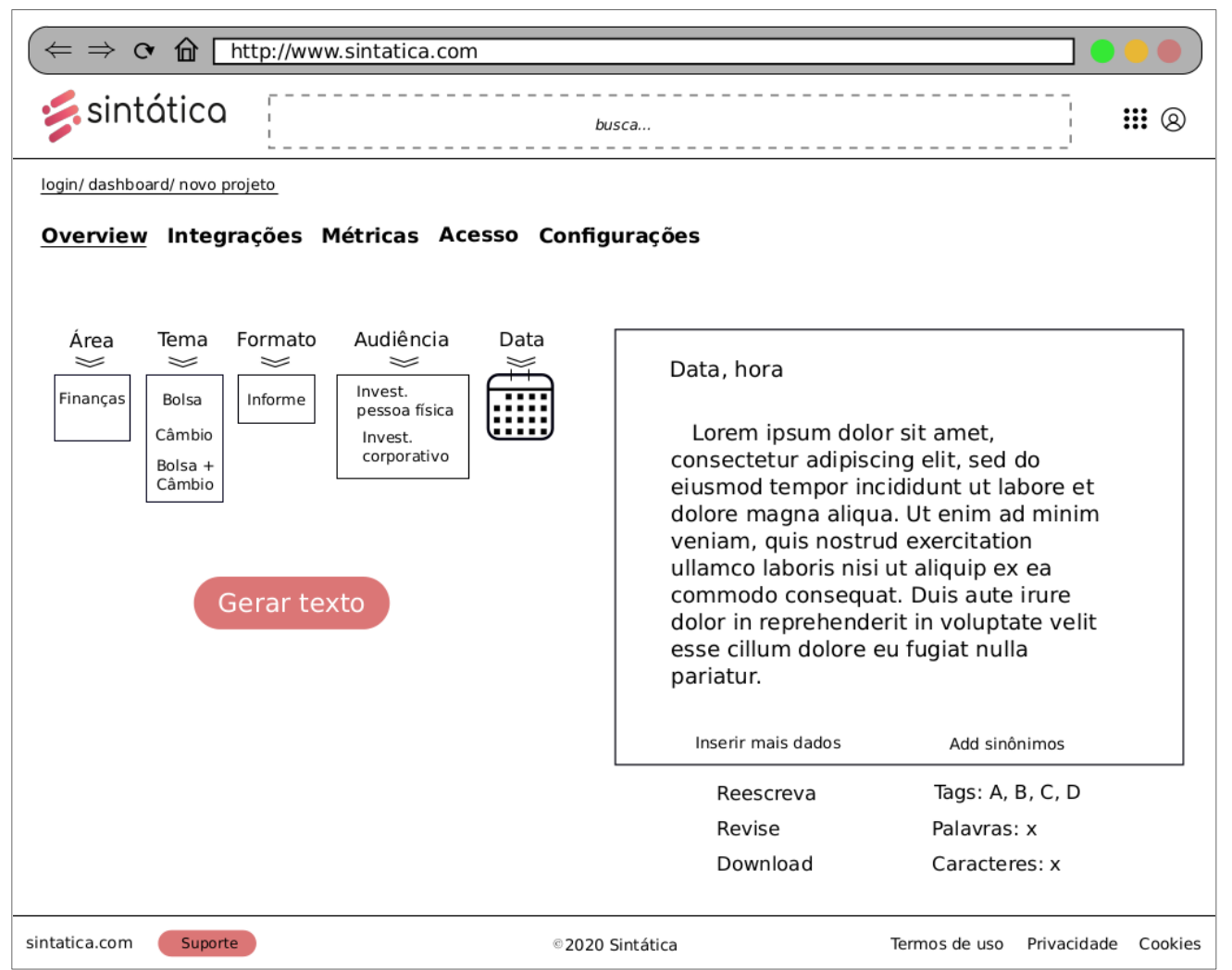

Fonte: Os autores.

Dito isso, neste primeiro momento, testamos a seguinte lógica macro do funcionamento do MVP (Figura 10), a qual apresenta sete etapas para a produção do texto automatizado. Utilizamos como base as cinco etapas apresentadas por Graefe (2016), adaptando-as para a realidade deste projeto. No que segue, os números entre parênteses referem-se às 7 etapas mencionadas acima e às figuras da figura 10 abaixo.

Após o usuário estar conectado à plataforma com login e senha (1); ter gerado um novo projeto (2); e inserido os filtros na tela de geração de texto automatizado (3), ao clicar no botão "gerar texto", o usuário envia os dados de entrada (inputs) para o servidor banco de dados que possui o software de gerenciamento (hard code), assim como dados novos, históricos e contextualizados (4).

Em seguida, os algoritmos coletam/requisitam as APIs Yahoo Finance! e Alpha Vantage (média de delay de 15 minutos): pontuação Ibovespa; cotação de moeda estrangeira; variações e preços das ações; melhor e pior desempenho das empresas por setores (5), o que retorna para software de gerenciamento (hard code) com a análise de correlações dos dados e regras pré-definidas por tópicos. 


\section{Obsevisto}

e-ISSN no $2447-4266$

Palmas, v. 7, n. 3, p. 1-29, jul.-set., 2021 http://dx.doi.org/10.20873/uft.2447-4266.2021v7n3a9pt

Após essa etapa, mas ainda no software de gerenciamento, inicia-se a priorização dos insights a partir das regras predefinidas - onde acontece a organização dos elementos noticiosos predefinidos seguindo regras para gerar uma narrativa onde se encaixam os templates dinâmicos (6); por último ocorre a geração de output (7), ou seja, o texto automatizado gerado e enviado para o box de texto da tela 3 (ver figura 9) da interface web. Esse texto gerado pode ser publicado automaticamente, após integração com o sistema de gerenciamento e publicação do usuário/empresa, ou copiado pelo usuário e postado/publicado manualmente.

Figura 10. Lógica macro da infraestrutura do desenvolvimento do MVP.

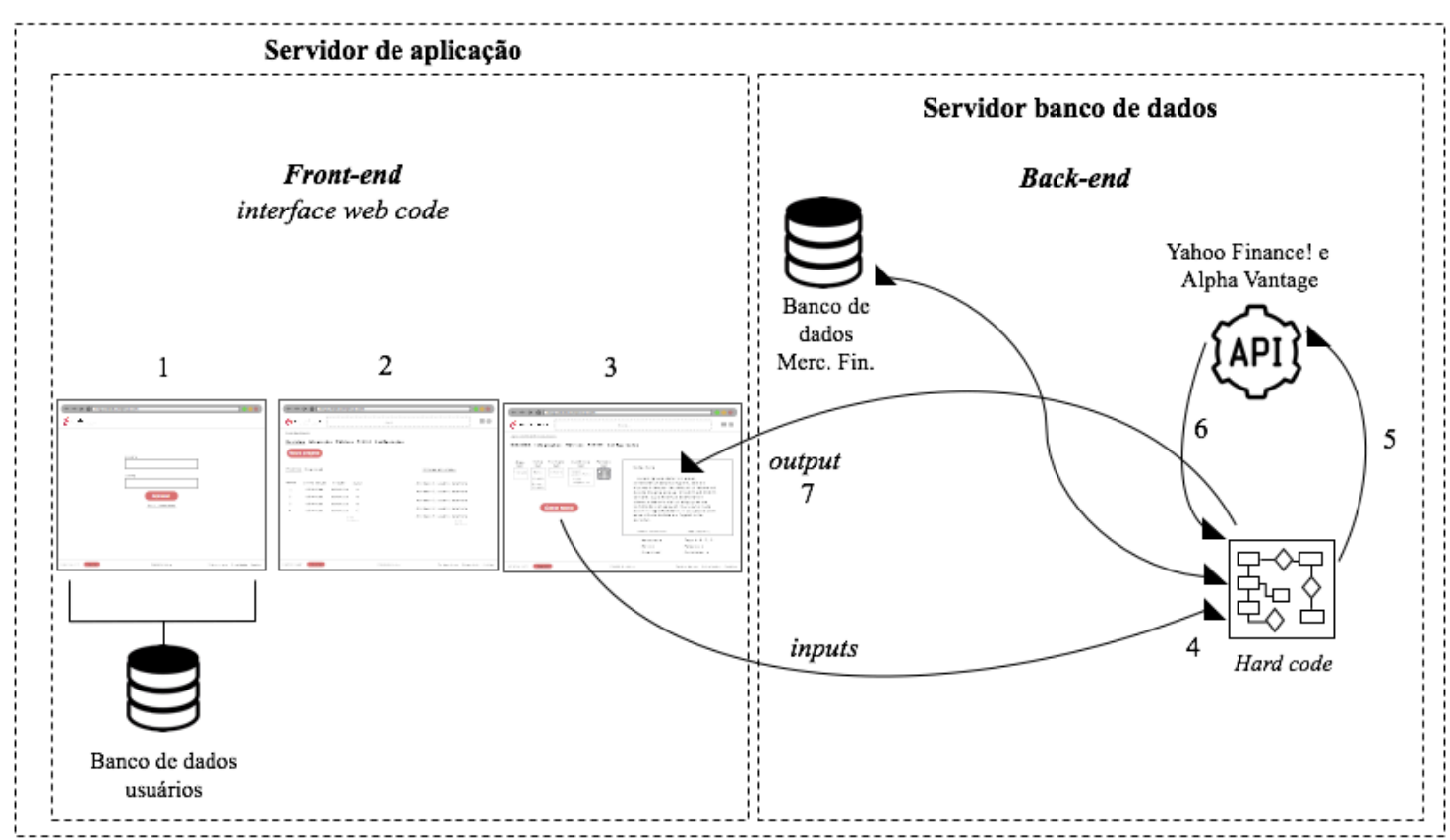

Fonte: Os autores e time de desenvolvimento do projeto.

O planejamento e o desenvolvimento do código contabilizaram por volta de 280 horas úteis de março/20 a janeiro/21. O MVP, até a última data citada, possui cerca de 42 mil linhas de programação.

\section{Memorial: processo de criação}

No primeiro semestre de 2019, iniciamos uma profunda jornada de investigação e compreensão do que estava sendo pesquisado, desenvolvido e aplicado em universidades, startups, jornais e agências de notícias pelo mundo sobre textos automatizados. 


\section{Obevisto}

e-ISSN n² 2447-4266

Palmas, v. 7, n. 3, p. 1-29, jul.-set., 2021

http://dx.doi.org/10.20873/uft.2447-4266.2021v7n3a9pt

Ao decorrer desse mesmo ano, buscamos a equipe para desenvolver o newsbot direcionado para organizações não jornalísticas. Conversamos com alguns desenvolvedores a respeito da apresentação do projeto, possibilidades de desenvolvimento do produto, Interface de Programação de Aplicações (APIs, sigla em inglês), tempo, investimento e processo de execução.

As possibilidades afloraram, o que nos ajudou a ter uma visão macro do projeto e saber se estávamos indo na direção certa. Porém, nenhuma equipe aceitou desenvolver o software por indisponibilidade de tempo.

Nessa etapa, seguimos com a pesquisa e o embasamento teórico e, em paralelo a isso, participamos de congressos de comunicação e do Startup Católica de Brasília, para mapear a viabilidade econômica e financeira do projeto, assim como as premissas para compor em alguma medida o plano de negócios da startup Sintática, empresa de tecnologia em comunicação, que nasce, em fevereiro/2020, em paralelo à pesquisa acadêmica de mestrado que embasa este artigo.

Essa experiência fez com que pudéssemos olhar de maneira mais crítica alguns aspectos, como a aplicação de um questionário online para identificar a real necessidade do cliente; a própria lógica de desenvolvimento do MVP; a tentativa de fazer um pitch com cronômetro ligado; os aspectos administrativos, contábeis e jurídicos de uma empresa. A vivência foi positiva e aperfeiçoou a pesquisa, nosso espírito empreendedor.

Em 2020, entramos na comunidade online Python Brasil para contatar desenvolvedores que utilizam a linguagem de desenvolvimento do software. A comunidade prontamente respondeu com dicas de programação, exemplos e depoimentos, permitindo-nos perceber o quão ativa e colaborativa ela é. A partir daí, iniciamos conversas com outros desenvolvedores e membros da comunidade que se dispuseram a apoiar pontualmente o projeto.

Ainda em janeiro, o Desenvolvedor $\mathrm{A}^{4}$ oficializou o aceite, e, na ocasião foram definidas algumas etapas, como especificação e projeto, desenvolvimento e teste, assim como prazos.

O mês de fevereiro foi dedicado ao rascunho do funcionamento do newsbot, o qual escreveria a partir de dados estruturados, mas sem templates. Após o Exame de Qualificação, fizemos uma reflexão sobre qual caminho seguir em termos de viabilidade técnica e tempo de execução para o desenvolvimento do MVP.

4 Os desenvolvedores serão nomeados por letras que não estão associadas aos seus nomes. Escolhemos mencioná-los assim para que não haja nenhum tipo de exposição. 


\section{Obsevisto}

e-ISSN n² 2447-4266

Palmas, v. 7, n. 3, p. 1-29, jul.-set., 2021 http://dx.doi.org/10.20873/uft.2447-4266.2021v7n3a9pt

A versão proposta na Qualificação foi desconsiderada, porque impactaria completamente o desenvolvimento do software, já que a lógica de programação seria outra, demandando mais tempo, recursos e equipe. Ao analisar as possibilidades disponíveis, mudamos o curso da criação do protótipo, para que a modelagem do código-fonte hard code tivesse a adoção de templates, como se faz em boa parte dos projetos.

Depois disso, voltamos muitos passos do planejamento do MVP. Já sabíamos qual seria o novo caminho, mas tivemos que remodelar a forma de funcionamento do newsbot. Isso demandou horas de estudos e rascunhos até chegarmos à primeira versão. O curso de lógica de programação foi fundamental, pois nos apropriamos literalmente do pensamento computacional.

Devido à pandemia do novo coronavírus, o planejamento e a execução deste trabalho foram impactados e o cronograma sofreu ajustes. O Desenvolvedor A permaneceu no projeto de janeiro a junho de 2020 e selecionamos os Desenvolvedores B e C para seguir com o projeto, do ponto em que havíamos parado.

Nessa fase do MVP, incorporamos o framework Scrum, o que facilitou definir tarefas da sprint, estimativa de tempo, gerenciamento e transparência das atividades acordadas, assim como o pagamento das horas dedicadas ao projeto, trazendo dinamicidade ao desenvolvimento do MVP.

Após a contratação dos desenvolvedores B e C, nos vimos no fim de setembro/2020, com a necessidade de buscar novos integrantes para a equipe e começamos a questionar onde estavam as mulheres da engenharia de software, das ciências da computação, da matemática e porque nós não as encontravamos.

Deparamo-nos então com diversas comunidades que fomentam a participação de mulheres nas áreas STEM, como o PyLadies Brasil, PretaLab, Women who Code, Rails Girls, CodeGirl, MariaLab entre outras redes que dão voz a mulheres programadoras.

Acionamos o PretaLab, convidando algumas desenvolvedoras para um batepapo. A experiência foi positiva e teve como resultado a contratação da desenvolvedora $\mathrm{D}$ com perfil sênior, que se dedica ao projeto 20 horas semanais.

No início de dezembro, começou no projeto a Desenvolvedora E, focada em modelagem, povoamento, manutenção do banco de dados e conexões com as APIs. Dedicação de 20 horas semanais.

O projeto seguiu seu curso de julho de 2020 a janeiro de 2021, com 12 Sprints em que tivemos a programação de incrementos fundamentais para a estruturação do protótipo tanto no hard code, quanto no web interface code e banco de dados. 


\section{Obsevisto}

e-ISSN no 2447-4266

Palmas, v. 7, n. 3, p. 1-29, jul.-set., 2021 http://dx.doi.org/10.20873/uft.2447-4266.2021v7n3a9pt

Ao fim da Sprint12, alcançamos dois importantes resultados: a integração, realizada na quarta tentativa, dos códigos e banco de dados; isso levou ao segundo resultado: a produção do texto em si, incluindo os setores que fazem parte da Bolsa de Valores do Brasil, que já apareciam no box de texto da tela três.

Cabe dizer que o acesso de usuários, previamente cadastrados, se tornou possível no ambiente de desenvolvimento e consequentemente a navegação destes usuários pelo software.

Para fechar esta seção, a etapa que se refere ao desenvolvimento do MVP contou com dois desafios. O primeiro foi conceber, em sua totalidade, a lógica macro de funcionamento do software. São necessários diversos fatores, como diagramas, infraestrutura, servidores, integrações, modelagens e equipe, o que ultrapassa um script. Por mais que existam bibliotecas de código, ainda assim é necessário saber o quê, quando, como e para quê usar.

Carneiro (2016) explica por que esse conhecimento não é disponibilizado: as principais soluções já implementadas no mercado são oriundas de empresas privadas de Inteligência Artificial, que protegem seus processos de desenvolvimento e as equipes envolvidas. Hoje é possível acessar o código aberto disponibilizado pela OpenAl.

O segundo desafio consistiu na aquisição e na retenção de equipe especializada. Manejar esse assunto consome tempo e requer experiência em gestão de pessoas. Percebemos que, na ciência, não ter resultado ou ver que ele é completamente diferente do que se imaginava também é resultado.

\section{Considerações finais}

Este trabalho teve como objetivo desenvolver um MVP de uma plataforma web que transforma dados estruturados da Bolsa de Valores do Brasil em informes financeiros automatizados. Para isso, trilhamos um caminho em que a comunicação estratégica organizacional e a automação de conteúdo puderam se encontrar.

A compreensão dos aspectos estratégicos pode, em alguma medida, trazer luz a essa discussão, isso porque, no campo da comunicação, muitas vezes a estratégia tem aparecido como uma mola propulsora para aproximar as organizações cada vez mais de seus objetivos de negócio junto aos seus públicos.

Abordamos também a necessidade de se criar um design estratégico de mensagens cada vez mais alinhado aos diferentes tipos de audiência que tais organizações possuem, porque comunicar de forma massiva hoje tem sido menos 


\section{Obsevisto}

e-ISSN no 2447-4266

Palmas, v. 7, n. 3, p. 1-29, jul.-set., 2021 http://dx.doi.org/10.20873/uft.2447-4266.2021v7n3a9pt

efetivo, uma vez que o receptor escolhe e classifica o que deseja consumir e, a cada dia, ele quer se sentir único, desejando ter uma boa experiência; por isso, o design estratégico de mensagens faz-se cada vez mais necessário.

Pontuamos que não vemos os algoritmos como algo maléfico para nenhum dos atores envolvidos no processo de produção ou consumo de um texto escrito de maneira automatizada, mas a concentração de poder e pouco diálogo pode gerar e potencializar uma relação cada vez mais distante e distorcida entre o emissor e o receptor da mensagem.

No que tange ao estudo de manipulação experimental, alcançamos como resultado inicial o desenvolvimento da lógica macro da infraestrutura de funcionamento do MVP. Essa arquitetura foi fundamental para compreender como o newsbot funcionaria, orquestrando o trabalho do Time de Desenvolvimento e as prioridades para realização do projeto como um todo. $O$ desenvolvimento e testes incrementais do MVP da plataforma resultaram no acesso de usuários previamente cadastrados no ambiente de desenvolvimento, possibilitando a navegação pelo software e a geração dos primeiros textos/informes financeiros automatizados.

Como resposta à pergunta desta pesquisa: como uma organização financeira pode se valer da mediação algorítmica para gerir e utilizar os dados gerados, recebidos e armazenados, transformando-os em textos automatizados coerentes, chegamos à conclusão de que o newsbot pode ser uma solução mitigadora desse problema.

Porém, para que a organização tenha êxito, é necessário haver um trabalho estratégico com os atores envolvidos, a fim de que o produto não seja visto na instituição como um invasor, e os colaboradores da organização não ajam como anticorpos para expulsar essa inovação cmoo um intruso. O objetivo não é substituir pessoas, mas sim estabelecer um relacionamento híbrido em que humanos e máquinas trabalhem juntos, para que humanos tenham mais tempo de contribuir de maneira mais estratégica e inovativa.

O método hipotético-dedutivo associado aos métodos ágeis trouxe soluções concretas para a pesquisa, fazendo-nos ver que nada é fixo e rígido quando se trata de estratégia e inovação. Foi possível construir conclusões prováveis a partir da intuição científica, e a estratégia do newsbot não foi feita e seguida à risca: foi vivida diariamente e redirecionada a manter o foco no objetivo central do trabalho.

A inserção de uma camada de desenvolvimento para incorporar redes neurais artificiais ao newsbot é um incremento que se divide em inúmeros subincrementos. É como um bolo com cobertura: para aplicarmos essa cobertura, é necessário que todo o 


\section{Obsevisto}

e-ISSN no $2447-4266$

Palmas, v. 7, n. 3, p. 1-29, jul.-set., 2021

http://dx.doi.org/10.20873/uft.2447-4266.2021v7n3a9pt

processo: receita, escolha dos ingredientes, produção e cozimento, já tenha sido realizado. O mesmo acontece com o newsbot, e isso foi verificado no desenvolvimento. Porém, toda a infraestrutura já está sendo desenvolvida de maneira a receber a inteligência artificial no futuro próximo, meta além desta pesquisa.

Para concluir, o newsbot faz parte hoje de um projeto maior, advindo de uma pesquisa de mestrado. Ele seguirá em constante aperfeiçoamento e mais incrementos serão adicionados à plataforma, refinando o resultado por meio de várias versões até que o sistema esteja adequado, como citamos na metodologia deste trabalho.

Frisamos que, para o newsbot desta pesquisa ser um elemento estratégico de uma organização e produzir mensagens com design estratégico para o investidor, é necessário que esteja integrado ao planejamento institucional, de maneira que a CVM consiga imprimir em sua estratégia o agente transformador da inovação para agregar valor ao negócio e aos clientes.

\section{Referências}

ADOBE; ECONSULTANCY. Índice de Experiência: tendências digitais para 2019: Sumário executivo. London: Adobe, 2019. Disponível em:

https://www.adobe.com/content/dam/acom/en/modal-offers/econsultancydigital-trends-2019/pdfs/econsultancy-2019-digital-trends_US.pdf. Acesso em: 3 ago. 2020.

AZZELLINI, Erica Camillo; PESCHANSKI, João Alexandre. O conceito de Jornalismo Computacional ante as potencialidades das narrativas estruturadas. $I n$. CONGRESSO BRASILEIRO DE CIÊNCIAS DA COMUNICAÇÃO, 41., 2018, Joinville. Anais [...]. São Paulo: Intercom, 2018. p. 1-15.

BARICHELLO, E. M. M. da R. Apontamentos sobre as estratégias de comunicação mediadas por computador nas organizações contemporâneas. In: KUNSCH, Margarida Maria Krohling (org). Comunicação Organizacional: histórico, fundamentos e processos. Volume 1. São Paulo: Saraiva, 2009.

BEER, D. The Social Power of Algorithms. Information, Communication and Society, $[s$. l.], v. 20, n. 1, p. 1-13, 2017.

BIRD, S.; KLEIN, E.; LOPER, E. Natural Language Processing with Python. Sebastopol, CA: O'Reilly Media, 2009.

CARNEIRO, M. S. Comunicação Digital e Jornalismo de Inserção: como o big data, inteligência artificial, realidade aumentada e internet das coisas estão mudando a produção de conteúdo informativo. São Luís: Labcom Digital, 2016.

CODDINGTON, M. Clarifying Journalism's Quantitative Turn. Digital Journalism, [s. l.], v. 3, n. 3, p. 331-348, 2015.

CRUZ, F. Scrum e Agile em Projetos: guia completo. 2. ed. Rio de Janeiro: Brasport Livros e Multimídia, 2018.

DANS, E. Meet Bertie, Heliograf and Cyborg, the New Journalists on the Block. Forbes, [s. l.], 6 Feb. 2019.

DIAKOPOULOS, N. A Functional Roadmap for Innovation in Computational Journalism. [S. l.: s. n.], 2011. 
DIAKOPOULOS, N. Automating the News: how algorithms are rewriting the media. Cambridge, MA: Harvard University Press, 2019.

DJANGO. The Web Framework for Perfectionists with Deadlines. Kansas, EUA: Django, 2005.

DÖRR, K. N. Mapping the Field of Algorithmic Journalism. Digital Journalism, v. 4, n. 6, p. 700-722, 2016.

FERRARETTO, E. K. Assessoria de imprensa: teoria e prática. São Paulo: Summus, 2009.

GRAEFE, A. Guide to Automated Journalism. Columbia Journalism School, 2016.

HALLAHAN, K.; HOLTZHAUSEN, D.; RULER, B. V.; VERCIC, D.; SRIRAMESH, K. Defining strategic communication. International Journal of Strategic Communication, [s. l.], n. 1, p. 3-35, 2007. DOI: 10.1080/15531180701285244.

HEIDE, M.; PLATEN, S. V.; SIMONSSON, C.; FALKHEIMER, J. Expanding the scope of strategic communication: Towards a holistic understanding of organizational complexity. International Journal of Strategic Communication, [s. l.], v. 12, n. (4), p. 452-468, 2018. DOI: 10.1080/1553118X.2018.1456434.

HELBING, Dirk et al. Will Democracy Survive Big Data and Artificial Intelligence? Scientific American, [s. l.], 2017.

ISO. IEC. ISO/IEC 25010: System and Software engineering - System and software Quality Requirements and Evaluation (SQuaRE) - System and software quality models. Switzerland: ISO 2011.

KOTLER, P.; KARTJAJAYA, H.; SETIAWAN, I. Marketing 4.0. Tradução: Ivo Korytowski. Rio de Janeiro: Sextante, 2017.

LAKATOS, E. M. Fundamentos de Metodologia Científica. 7. ed. São Paulo: Atlas, 2010.

LOBO, R. N. Gestão da Qualidade. São Paulo: Érica, 2010.

MANOVICH, L. Trending: the promises and the challenges of big social data. [S. l: s. n.], 2011. Disponível em: http://manovich.net/index.php/projects/trending-thepromises-and-the-challenges-of-big-social-data. Acesso em: 19 set. 2019

MAYER-SCHONBERGER, V.; CUKIER, K. Big Data: como extrair volume, variedade, velocidade e valor da avalanche cotidiana. Rio de Janeiro: Campus, 2013.

MILOSAVLJEVIĆ, M. VOBIČ, I. Our task is to demystify fears: analysing newsroom management of automation in journalism. Journalism, [s. l.], p. 1-19, 2019.

OSTERWALDER, A.; PIGNEUR, Y. Business Model Generation Inovação em Modelos de Negócios: um manual para visionários, inovadores e revolucionários. Rio de Janeiro: Alta Books, 2011.

REITER, E.; DALE, R. Building Natural Language Generation Systems. Cambridge: Cambridge University Press, 2000.

RUÃO, T. Organização Comunicativa: teoria e prática em comunicação organizacional. Braga: CECS, 2016.

SARAIVA, E. V.; CARRIERI, A. de P.; AGUIAR, A. R. C.; BRITO, V. da G. P. Um "pas de deux" da estratégia com a arte: as práticas do Grupo Corpo de balé. RAC, [s. l.], v. 15, n. 6, 2011.

SOMMERVILLE, I. Engenharia de Software. Tradução Luiz Cláudio Queiroz. 10. ed. São Paulo: Person Education do Brasil, 2018.

SOMMERVILLE, I. Engenharia de Software. Tradução: Selma Shin Shimizu Melnikoff, Reginaldo Arakaki, Edílson de Andrade Barbosa. 8. ed. São Paulo: Pearson Addison Wesley, 2007.

STRAUSS, N. Financial journalism in today's high-frequency news and information era. Journalism, [s. l.], p. 1-18, 2018.

TABARY, C.; PROVOST, A.-M.; TROTTIER, A. Data journalism's actors, practices and skills: a case study from Quebec. Journalism, [s. l.], p. 1-19, 2015.

VOLK, Sophia Charlotte; BERGER, Karen; ZERFASS, Ansgar; BISSWANGER, Luisa; FETZER, Marcus; KOHLER, Karolin. How to play the game: Strategic tools for managing 


\section{Obsevisto}

corporate communications and creating value for your organization. Leipzig, Germany: Academic Society for Management \& Communication, 2017.

WÖLKER, A; POWELL, T. E. Algorithms in the newsroom? News readers' perceived credibility and selection of automated journalism. Journalism, [s. l.], p. 1-18, 2018.

WOLTON, D. Informar não é comunicar. Porto Alegre: Sulina, 2011.

ZERFASS, A.; VERCIC D.; NOTHHAFT, H.; WERDER, K. P. Strategic Communication: Defining the Field and its Contribution to Research and Practice. International Journal of Strategic Communication, [s. l.], v. 12, n. 4, p. 487-505, 2018. DOI: 10.1080/1553118X.2018.1493485.

\begin{abstract}
:
This research aims to develop the Minimum Viable Product (MVP) of a cloud platform that transforms structured data into automated text, to enhance the production of content in Brazilian stock brokerage companies. It is based on applied research that combines different techniques for the development of MVP. As a theoretical path to support product development, it permeates strategic communication in corporations, as well as the adoption of algorithms and content automation in journalistic production. Among the results achieved, the work presents the logic of infrastructure of macro operation for the newsbot and the main elements for the many layers of development that an application of this nature needs.
\end{abstract}

KEYWORDS: Strategic Communication; Organizational strategy; Automated content; Newsbot; Algorithms.

\section{RESUMEN:}

Esta investigación objectiva desarrollar el Minimum Viable Product (MVP) de una plataforma en la nube que transforma datos estructurados en textos automatizados, para potenciar la pro

ducción de contenido de Corretajes de Valores. Se trata de una Investigación Aplicada que combina diferentes técnicas para el desarrollo de MVP. Como camino teórico para apoyar el desarrollo del producto, traspasa la comunicación estratégica en las corporaciones, así como la adopción de algoritmos y automatización de contenidos en la producción periodística

Como algunos de los resultados alcanzados, el trabajo presenta la lógica de infraestructura macro de la operación del newsboty los elementos principales para las innumerables capas del desarrollo que una aplicación de esta naturaleza necesita.

$\begin{array}{llr}\text { PALABRAS-CLAVES: } & \text { Comunicación } \\ \text { estratégica; } & \text { Estrategia } & \text { organizacional; } \\ \text { Contenido } & \text { automatizado; } & \text { Newsbot; } \\ \text { Algoritmos } & & \end{array}$

